Ethics

\section{Spinal muscular atrophy-type I}

\section{K M Hardart, R D Truog}

The challenge of defining a child's best interests

S pinal muscular atrophy-type I or Werdnig-Hoffman disease is an autosomal recessive disorder of childhood that causes profound weakness and death from respiratory failure, typically by the age of 2 years in the absence of mechanical ventilation. ${ }^{2}$ Management of this condition is highly variable-while some patients and their families are not offered any form of respiratory support, patients in other settings are routinely treated with the full spectrum of respiratory assistance and supportive care. ${ }^{3}$ Unless this striking variability in practice can be justified on the basis of factors related to individual differences between patients, it must represent either a failure to appreciate key factors about the disease or the influence of professional values and norms on the decision making process.

\section{THE UNDERLYING PROBLEM}

The spinal muscular atrophies (SMA) are a spectrum of inherited neuromuscular diseases caused by the degeneration of anterior horn cells. The SMAs are categorised into stages based on age of onset, with type I defined by evidence of weakness before 6 months of age. ${ }^{4}$ While patients with this disorder have normal intellect, they generally have rapid neuromuscular deterioration and suffer a respiratory death in the first two years of life. ${ }^{12}$ Those patients with other forms of SMA have later onset of symptoms, experience a slower progression of muscle weakness, and respiratory symptoms may not arise until the teenage or adult years. The physician must be careful, however, when using this classification scheme to prognosticate for a given child. Several studies have cited many examples of children with onset of symptoms before age 6 months who have not developed respiratory failure for years. ${ }^{2-6}$ While $93 \%$ of all SMA patients are lacking a "survival motor neurone gene", ${ }^{-9}$ the genetic basis for phenotypic variability remains elusive. ${ }^{10-12}$ Thus, the prognosis for each child must be defined not by the subtype of the disease but by individual disease progression.

\section{SPECTRUM OF OPTIONS FOR MANAGEMENT OF RESPIRATORY FAILURE}

The development of non-invasive modes of mechanical ventilation and technology facilitating home respiratory support has brought a new dimension to the management of many neuromuscular diseases once considered uniformly lethal. ${ }^{13-18}$ Indeed, respiratory support has become a more commonly accepted option for victims of spinal cord injury, Duchenne muscular dystrophy (DMD), amyotrophic lateral sclerosis (ALS), and the milder, later onset forms of SMA. ${ }^{19-21}$ In contrast, patients with SMA-type I are inconsistently offered respiratory support, as shown in our recent report on physician beliefs and clinical behaviours regarding SMA-type I. ${ }^{3}$ This study, which surveyed paediatric rehabilitation physicians, neurologists, and intensivists, described wide variations within and between disciplines with regard to the practice of offering and/or recommending non-invasive mechanical ventilation, intubation, and tracheostomy to children with SMA-type I. Profound practice differences were found most strikingly between rehabilitation physicians and intensivists, with the former significantly more likely to offer and recommend all modes of mechanical ventilation.

The literature on SMA confirms the wide variability in clinical practice suggested by our survey. Several textbooks in paediatrics and neurology describe SMA-type I as a death sentence, and recommend against providing assisted forms of ventilation. ${ }^{22}{ }^{23}$ The Japanese literature reflects a markedly different approach, routinely treating children with SMA-type I with mechanical ventilation and questioning the morality of the Western practice of nonintervention. ${ }^{24} 25$ John Bach, a leading proponent of respiratory support for children with SMA-type I, has provided the bulk of what is published on the subject in the United States. Bach advocates the use of non-invasive mechanical ventilation and reports a series of 11 children with SMA-type I whose respiratory failure has been primarily managed non-invasively with nasal or mouthpiece intermittent positive pressure ventilation and mechanically assisted cough devices. ${ }^{26}$ Other reports in the literature are quite limited, often describing children who are mechanically ventilated only after a severe hypoxic event resulting in ischaemic brain injury. ${ }^{27}{ }^{28}$ In contrast to the medical literature, information available on the internet suggests relatively widespread use of mechanical respiratory support for SMA-type I patients. ${ }^{29}{ }^{30}$ Indeed it is concerning that SMA families who consult the internet for information may get an unbalanced perspective due to the strong bias towards providing mechanical ventilation among those families who participate in the internet groups. Equally disturbing is the potential that parents who turn to the internet for support after the death of a child with SMA-type I, may discover that they did not have the opportunity to make a fully informed choice with regard to available therapeutic options. While providing a valuable forum for community discussions, information sharing, and emotional support, the internet has become a powerful influence on family expectations, adding yet another dimension to be integrated into the already complex process of caring for a child with SMA-type I.

\section{WHAT IS A PHYSICIAN TO} RECOMMEND?

What factors explain the discrepancies between experts in the management of this disease? Perhaps those who do not offer respiratory support to their patients do not believe that mechanical ventilation prolongs survival. It is clear however, from the medical literature and a growing body of information on the internet that mechanical ventilation can effectively prolong survival in some children. ${ }^{25-27} 2930$ Consequently, the practice of not offering support must reflect concerns beyond the efficacy of the therapy to prolong life. As suggested by our recent study, physician attitudes towards mechanical ventilation in SMA significantly influence family decision making. Indeed, we found that those physicians who considered any form of mechanical ventilation to be unreasonable, were significantly more likely to have parents elect comfort care only for their child.

Why is it that many physicians consider mechanical ventilation in SMAtype I unreasonable? Perhaps physicians consider the practice of ventilating these children fiscally and thus socially irresponsible. Estimates of the cost of home ventilator care vary. One group of investigators estimated the yearly cost of noninvasive mechanical ventilation to be $\$ 5220$ and that for invasive mechanical ventilation with 16 hours/day of nursing care to be $\$ 199500 .{ }^{31}$ This translates into $£ 32412$ (€48 900) for non-invasive mechanical ventilation and £123867 
(€186 885) for invasive mechanical ventilation. Taking into consideration the cost of lost income, physician, hospital and inpatient days, and monthly annualised cost of one-time purchases and/or home remodelling, another group estimated total yearly cost of invasive mechanical ventilation with nursing support to be \$103152 (range \$2626$365904)^{32}$ or £64045 (range £1630227185 ) (equivalent to $€ 96161$ with a range of €2460-342 767). These estimates, determined for adult ventilated patients, likely underestimate the cost of caring for a child with SMA as they do not consider cost of home or specialised schooling. It is not surprising then, with the growing trend to spend medical resources wisely, that the chronically ventilated population is a natural target for scrutiny. However, in our social climate of relative prosperity, decisions made by adults with ALS, DMD, and spinal cord injury to undergo mechanical ventilation are generally considered reasonable. Similar standards should thus be applied to the provision of respiratory support of children with SMA-type I.

\section{"Anecdote and clinical judgement guide physician decision making"}

Perhaps the uncertainty of success of mechanical ventilation in SMA-type I compels physicians to consider it unreasonable. Certainly, some children with SMA suffer from a very aggressive form of the disease, developing distress from progressive kyphoscoliosis and multiple aspiration pneumonias not responsive to mechanical ventilation. ${ }^{33}$ However, many do not. While the long term outcome of patients with SMA-type I who receive respiratory support is indeed uncertain, uncertainty in itself is not often a compelling reason to withhold therapy. Consider the child born with hypoplastic left heart syndrome, a serious heart defect that requires a series of three major corrective procedures and still holds a five year actuarial survival rate of only $54-70 \%$. $^{34-37}$ Many families choose this course of treatment with the knowledge that their child will endure discomfort of the surgical procedures; risk complications of infection, neurological sequela, and respiratory distress; possibly succumb to the complications of the disease before undergoing the definitive palliative procedure; and finally, may undergo all three procedures only to require cardiac transplantation or to live a life of cardiopulmonary disability of uncertain longevity. While not every family agrees to this course of therapy, the widespread acceptance of this as a standard of care reflects a tolerance to uncertainty regarding long term outcomes.
Perhaps, however the issue motivating a physician's decision not to offer mechanical ventilation to a child with SMA-type I is not the uncertainty of the outcome but the perception that the quality of life of a chronically ventilated child is below the threshold that would justify treatment. As there are no studies examining the quality of life of ventilated SMA-type I patients, anecdote and clinical judgement guide physician decision making. Unfortunately, physicians have historically been poor estimators of life satisfaction of chronically ventilated persons. While acceptance of mechanical ventilation for patients with ALS and DMD has increased significantly over the past decade, enthusiasm for this technology was initially scant. In 1985, Colbert and Schock surveyed directors of Muscular Dystrophy Association (MDA) clinics regarding prescription of ventilatory aids to patients with DMD and found that only $33 \%$ of the MDA clinics routinely offered respiratory assistance to their patients. ${ }^{38}$ A few clinicians cited cost, prolongation of suffering, and family burden as reasons for not prescribing mechanical ventilators. Hypothesising that practices would change over time with advancement of respiratory technology, John Bach repeated a survey of MDA clinic directors and co-directors in $1990 .{ }^{39}$ Results were startlingly similar to those of Colbert and Schock, with ventilatory assistance recommended and used on an elective basis in only $26 \%$ of the responding clinics. The study also found that in $41 \%$ of clinics (68) with a policy discouraging use of long term ventilation, poor patient quality of life was cited as the most frequent reason $(68 \%)$ for withholding ventilatory aid. Bach then asked 80 ventilator dependent MDA patients to rate life satisfaction and compared these responses to MDA clinic directors' perceptions of ventilator users' life satisfaction. In general the physicians significantly underestimated patient's satisfaction with life, and those who routinely discouraged use of chronic ventilation were even less accurate in their estimation of patient life satisfaction. In a second evaluation of life satisfaction among DMD patients using long term mechanical ventilation, Bach found healthcare workers involved with the care of DMD patients significantly underestimated life satisfaction of DMD patients. ${ }^{40}$ Additionally, of the 80 ventilator dependent DMD patients surveyed, every patient without exception, indicated that ventilatory assistance should be offered to all individuals who might benefit. Certainly without adequate quality of life assessments for chronically ventilated children with SMA-type I and with a precedent of physician inability to make accurate quality of life assessments for other chronically ventilated patients, physicians should be cautious when making recommendations based on their own predictions of the patient's future quality of life.

Aside from questions about how to assess a patient's future quality of life, there remain unresolved questions about how to make decisions on behalf of an infant. Law and ethics both support a standard of decision making based on the "best interests" of the child. ${ }^{41}$ This leaves the question of who is in the best position to judge the child's best interests, and what factors can be included in the deliberation. The emerging standard of family centred decision making would argue the parents should have the dominant role in deciding what should be done for their child. The arguments for this prerogative are that most parents are deeply committed to their child's wellbeing, children are more likely to share the values of their parents as they grow up, and parents will bear the consequences of decision making. Controversy exists, however, on the moral relevance of family impact in decision making for a given patient. Consider, for example, a young unwed mother without social supports whose decision to chronically ventilate a child may prevent her from completing high school, marrying, or ever achieving financial independence from welfare services. Or consider a family with several children for whom the decision to chronically ventilate an additional child will impose such financial hardship that the other children may not be able to attend college. Some contend families should be able to make decisions guided by the estimated suffering incurred by all family members affected by that decision..$^{42}$ Others argue that we should firmly adhere to the traditional ethical principle of considering only the needs of the patient, without regard to the impact on others. While families are most often willing to make great sacrifices to meet the needs of their own, the limits to which the needs of the family can be balanced against the needs of the child is an area that is not well defined in either ethics or law.

\section{"The greatest challenge is anticipating what each family would consider adequate quality of life for their child"}

With the intent to help physicians define their role in family decision making, Ezekiel and Linda Emanuel describe the deliberative model in which the aim of the physician-patient interaction is to help the patient determine and choose the best health related values that can be realised in the clinical situation..$^{43}$ The Emanuels assert that the ideal physician does not act merely as a communicator of factual information, but rather acts as 
a friend or teacher who must try to "persuade" without coercion the "worthiness of certain values". The ultimate determination of a given child's best interests must be the upshot of a dynamic interchange between the physician and the family that has included careful consideration of the option to elect palliative care, discussion of the various modes of ventilatory assistance, and an exploration of family values and expectations. The physician must try to present a realistic concept of the long term implications of chronic ventilation and the financial, emotional, social, and medical burdens it entails. The physician must also help the family determine the feasibility of caring for a chronically ventilated child in their social context. For those families who elect palliative care only, the physician must prepare them for the type of death their child might experience. Perhaps the greatest challenge however, in preparing families to live with their ultimate decision is anticipating what each family would consider adequate quality of life for their child. Certainly without quality of life assessments of ventilated SMA-type I patients and in light of physicians' historical inability to accurately assess a chronically ventilated patient's quality of life, the physician is at great risk of inadequately preparing a family for the sequela of their decisions. The physician is thus challenged to help the family explore its concept of quality of life, while emphasising the values that the physician has grown to appreciate through experience with other children with SMA-type I. Regardless of a family's ultimate decision, it is essential that they receive assurance from their physician that he will be there to support them through the many challenges their chosen option entails.

Every child with SMA-type I is unique in his or her disease process, family ideals, resources, and expectations. As such, the care of each child should be individualised to suit the child's needs. Variations in the care of children with this disease should not primarily reflect the personal or professional norms of the caretakers, but rather be the outcome of a deliberative interaction that includes an appraisal of the medical facts as well as the values, aspirations, and normative views of the family.

\section{Arch Dis Child 2003;88:848-850}

\section{Authors' affiliations}

M K M Hardart, R D Truog, Department of Anesthesia, Children's Hospital, Harvard Medical School, Boston, MA, USA
Correspondence to: $\operatorname{Dr} M$ K M Hardart, Department of Anesthesia, Farley 517/MICU office, 300 Longwood Avenue, Boston, MA 02115, USA; katiemoyn@aol.com

\section{REFERENCES}

Iannaccone ST, Browne RH, Samaha FJ, et al. Prospective study of spinal muscular atrophy before age 6 years. Pediatr Neurol 1993;9:187-93.

2 Zerres K, Rudnick-Schoneborn S. Natural history in proximal spinal muscular atrophy. Arch Neurol 1995:52:518-23.

3 Hardart MKM, Burns J, Truog R. Respiratory support in spinal muscular atrophy-type I: a survey of physician practices and attitudes. Pediatrics 2002;110:e24.

4 Munsat TL, Davies KE. Meeting report: International SMA Consortium meeting. Neuromusc Disord 1992;2:423-8.

5 Dubowitz V. Chaos in classification of spinal muscular atrophies of childhood. Neuromusc Disord 1991;1:77-80.

6 Russman BS, lannacone ST, Buncher FJ, et al. Spinal muscular atrophy: new thoughts on the pathogenesis and classification schema. J Child Neurol 1992;7:347-53.

7 Lefebvre S, Burglen L, Reboullet S, et al. Identification and characterization of a spinal muscular atrophy-determining gene. Cell 1995;80: 155-65

8 Brustowicz LM, Lehner T, Castilla $\mathrm{LH}$, et al. Genetic mapping of chronic childhood-onset spinal muscular atrophy to chromosome 5q11.2-13.3. Nature 1990;344:540-1.

9 Melki J, Abdelhak S, Sheth MF, et al. Gene for chronic proximal spinal muscular atrophies maps to chromosome 5q. Nature 1990;344:767-8

10 Crawford TO. From enigmatic to problematic: the new molecular genetics of childhood spinal muscular atrophy. Neurology 1996:46:335-40

11 Scharf JM, Endrizzi MG, Wetter A, et al. Indentification of a candidate modifying gene for spinal muscular atrophy by comparative genomics. Nat Genet 1998;20:83-6.

12 Taylor JE, Thomas NH, Lewis CM, et al. Correlation of SMNt and SMNc gene copy number and survival in spinal muscula atrophy. Eur J Hum Genet 1998;6:467-74.

13 Gardner-Medwin D. Clinical features and classification of the muscular dystrophies. $\mathrm{Br}$ Med Bull 1980;36:109-15.

14 Sivak ED, Gipson WT, Hanson MR. Long-term management of respiratory failure in amyotrophic lateral sclerosis. Ann Neurol 1982:12:18-23.

15 Rideau Y, Gatin G, Bach J, et al. Prolongation of life in Duchenne's muscula dystrophy. Acta Neurol 1983;5:1 18-24.

16 Bach JR, O'Brien J, Krotenberg R, et al. Management of end stage respiratory failure in Duchenne muscular dystrophy. Muscle Nerve 1987; 10:177-82

17 Gilgoff IS, Kahlstrom E, MacLaughlin E, et al. Long-term ventilatory support in spinal muscular atrophy. J Pediatr 1989;1 15:904-9.

18 Curran FJ, Colbert AP. Ventilator management in Duchenne muscular dystrophy and postpoliomyelitis syndrome: twelve years experience. Arch Phys Med Rehabil 1989;70:180-5.

19 Bach JR, Wang TG. Noninvasive long-term ventilatory support for individuals with spinal muscular atrophy and functional bulbar musculature. Arch Phys Med Rehabil 1995;76:213-17.

20 Miller RG, Rosenberg JA, Gelinas DF, et al. Practice parameter: the care of the patient with amyotrophic lateral sclerosis (an evidence-based review): report of the Quality Standards Subcommittee of the American Academy of Neurology. Neurology 1999;52:1311-36.
21 Servera E, Gomez-Merino E, Perez D, et al. Home mechanical ventilation in amyotrophic lateral sclerosis patients is not always a problem. Chest 2000;1 17:924.

22 Ouvrier R, Rapin I. The neuromuscular system: childhood anterior horn cell disease and peripheral neuropathies. In: Rudolph AM, Rudolph CD, eds. Rudolph's pediatrics, 21 st edn. Stamford, CT: Appleton and Lang 2001:2279-85.

23 Volpe JJ. Neuromuscular disorders. In: Volpe, ed. Neurology of the newborn, 3rd edn. Phildelphia, PA: W Saunders and Co. 1995:608-12.

24 Hayashi H. Ventilatory support: Japanese experience. J Neurol Sci 1977; 152(suppl 1):97-100

25 Sakakihara Y, Yamanaka T, Kajii M, et al. Long-term ventilator-assisted children in Japan: an national survey. Acta Paediatr Jpn 1996;38:137-42.

26 Bach JR, Niranjan V, Weaver BS. Spinal muscular atrophy type 1: a noninvasive respiratory management approach. Chest 2000;117:1100-5

27 Wang TG, Bach JR, Avilla BS, et al. Survival of individuals with spinal muscular atrophy on ventilatory support. Am J Phys Med Rehabil 1994;73:207-11.

28 Birnkrant DJ, Pope JF, Martin JE, et al. Treatment of type I spinal muscular atrophy with noninvasive ventilation and gastrostomy feeding. Pediatr Neurol 1998;18:407-10.

29 Families of Spinal Muscular Atrophy. Home page. Available at: http:// www.fsma.org. 20 December 2000

30 Infantile Progressive Spinal Muscular Atrophy (SMA, SMAI, or WH), (also known as SMA type I, Werdnig-Hoffman). Resource page. Muscular Dystrophy Association website. Available at: http:// www.mdausa.org/disease/sma/.html

31 Klein LM, Forshew DA. The economic impact of ALS. Neurology 1996;47(4 suppl 2):s126-9.

32 Sevick MA, Kamlet MS, Hoffman LS, et al. Economic cost of home-based care for ventilator-assisted individuals: a preliminary report. Chest 1996;109:1597-606.

33 MacLeod MJ, Taylor JE, Lunt PW, et al. Prenatal onset spinal muscular atrophy. Eur J Paediatr Neurol 1999;3:65-72.

34 Aeba R, Katogi T, Takeuchi S, et al. Long-term follow-up of surgical patients with single-ventricle physiology: prognostic anatomical determinants. Cardiovasc Surg 1997;5:526-32.

35 Kern JH, Hayes CJ, Michler RE, et al. Survival and risk factor analysis for the Norwood procedure for hypoplastic left heart syndrome. Am J Cardiol 1997;80:170-4

36 Bove EL. Current status of staged reconstruction for hypoplastic left heart syndrome. Pediatr Cardiol 1998;19:308-15.

37 Williams DL, Gelijns AC, Moskowitz AJ, ef al. Hypoplastic left heart syndrome: valuing the survival. J Thorac Cardiovasc Surg 2000;119(4 pt 1):720-31.

38 Colbert AP, Schock NC. Respirator use in progressive neuromuscular diseases. Arch Phys Med Rehabil 1985;66:760-2.

39 Bach JR. Ventilator use by muscular dystrophy association patients. Arch Phys Med Rehabil 1992;73:179-83.

40 Bach JR, Campagnolo D, Hoeman S. Life satisfaction of individuals with Duchenne muscular dystrophy using long-term mechanical ventilatory support. Am J Phys Med Rehabil 1991;70:129-35.

41 Beauchamp T, Childress J. Nonmaleficence. In: Beauchamp T and Childress J, eds. Principles of biomedical ethics, 4th edn. New York, NY: Oxford University Press, 1994:214-18

42 Hardwig J. What about the family? Hastings Center Report 1990;20:5-10.

43 Emanuel EJ, Emanuel LL. Four models of the physician-patient relationship. JAMA 1992;267:2221-6. 